\title{
O SAIRÉ COMO EXPRESSÃO SOCIOCULTURAL DOS DESCENDENTES DE POVOS INDÍGENAS DO BAIXO AMAZONAS/PA: PRÁTICA RESULTANTE DO PROCESSO CIVILIZATÓRIO JUNTO AOS ÍNDIOS BORARI
}

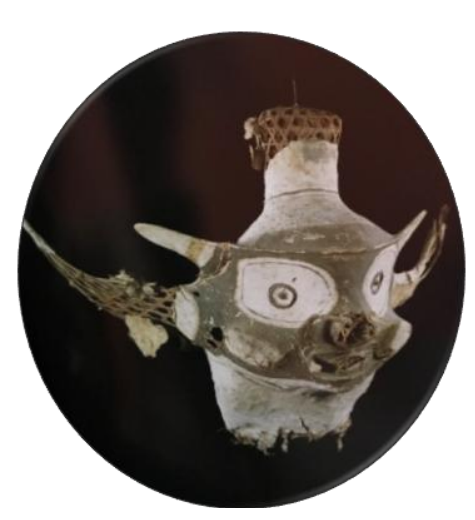

João Aluizio Piranha Dias1

Iraildes Caldas Torres2

\begin{abstract}
Resumo
O presente trabalho faz parte dos estudos e pesquisa que se encontram em andamento no curso de doutorado do Programa de Pós-graduação Sociedade e Cultura na Amazônia da Universidade Federal do Amazonas (PPGSCA/UFAM). O objetivo é analisar como as missões religiosas, em especial, a Companhia de Jesus, atuaram sobre grupos étnicos com intuito de converter, catequizar e civilizar povos indígenas da Amazônia brasileira, a partir da configuração do Sairé - semicírculo feito de cipó revestido de algodão, fitas coloridas e espelhos contendo em suas extremidades cruzes simbolizando as três pessoas da Santíssima Trindade e no ápice uma cruz maior representado a figura do Deus Único -, acompanhado de cantos, orações e procissões. E compreender como esses elementos da estratégia civilizatória dos missionários jesuítas, considerando suas ressignificações, mantém-se presentes na expressão sociocultural dos descendentes dos povos Borari da vila de Alter do Chão/PA, manifestados na festa do Sairé. O estudo tem como aporte teórico as contribuições de Norbert Elias sobre o processo civilizador no contexto da sociedade moderna e pós-moderna, além de contar com informações coletadas pelo método da história oral junto aos comunitários de Alter do Chão, através do uso intenso de entrevistas e do registro etnográfico na tentativa de entender as figurações que compõem a festa que louva a Santíssima Trindade e o Divino Espírito Santo. Caracteriza-se como um estudo de cunho qualitativo.
\end{abstract}

Palavras-chave: Processo Civilizador, Povos Indígenas, Amazônia, Sairé.

1 Doutorando do Programa de Pós-graduação Sociedade e Cultura na Amazônia - PPGSCA/UFAM.

2 Professora do Programa de Pós-graduação Sociedade e Cultura na Amazônia - PPGSCA/UFAM. 


\begin{abstract}
Este trabajo forma parte de los estudios e investigaciones que se están realizando en el programa de doctorado del Programa de Graduados de Sociedad y Cultura en la Universidad Federal de Amazonas Amazon (PPGSCA / UFAM). El objetivo es analizar las misiones religiosas, en particular, la Compañía de Jesús, actuó sobre los grupos étnicos con el fin de convertir, evangelizar y civilizar a los pueblos indígenas de la Amazonia brasileña, desde la configuración Sairé - semicírculo de algodón recubierto de bejuco, cintas de colores y espejos que contienen en sus extremos cruces simbolizan las tres personas de la Santísima Trinidad y la mayor cruz ápice representada la figura del Dios Único - acompañado de cantos, oraciones y procesiones. Y la comprensión de cómo estos elementos de la estrategia civilizadora de los misioneros jesuitas teniendo en cuenta su reinterpretación, permanece presente en la expresión social y cultural de los descendientes de las personas Borari de la villa de Alter do Chão / PA, que se manifiesta en el partido Sairé. El estudio es el soporte teórico de las contribuciones de Norbert Elias en el proceso de civilización en el contexto de la sociedad moderna y post-moderna, y se basan en información recogida por el método de la historia oral en el Alter do Chão comunidad a través de entrevistas intensivas y registro etnográfico para tratar de entender las figuraciones que componen el partido alabar a la Santísima Trinidad y el Espíritu Santo. Se caracteriza como un estudio de naturaleza cualitativa.
\end{abstract}

Keywords: Proceso de la civilización, Los pueblos indígenas del Amazonas, Saire.

\title{
INTRODUÇÃO
}

O presente trabalho é parte da pesquisa de doutorado que se encontram em andamento do Programa de Pós-graduação Sociedade e Cultura na Amazônia da Universidade Federal do Amazonas PPGSCA/UFAM. É um prosseguimento do mestrado e seu objetivo foi analisar como as missões religiosas, em especial, a Companhia de Jesus, atuaram sobre os grupos étnicos da Amazônia brasileira, a partir do século XVII com o intuito de converter, catequizar e civilizar os povos indígenas desta parte do país. O aporte teórico é sustentado pelas leituras, debates e reflexões ocorridas na disciplina eletiva Processo Civilizador e Práticas Socioculturais em Comunidades Amazônicas, ministrada no curso pelo Professor Dr. Gláucio Campos.

Por ser uma temática ampla, optamos em fazer um recorte espacial para melhor se compreender esse processo na região. Dessa feita, o 
trabalho tem como ponto de partida a festa do Sairé que se realiza na vila de Alter do Chão/PA.

Os jesuítas adentraram na Amazônia no início do século XVII e com eles o desejo de, em nome da fé católica e da coroa portuguesa, converter o maior número possível de nativos ao cristianismo, instruí-los e ensinar-lhes os modos e costumes da sociedade europeia que com ares e estilo de modernidade começava a se preocupar com comportamentos e atitudes, principalmente dos povos do Novo Mundo, que apresentavam formas de viver e entender o mundo de maneira diversa daquela dos europeus.

Comportamentos que aos olhos dos missionários eram vistos como "maus costumes" e "dessemelhantes" como a nudez, a poligamia, a antropofagia, os cultos aos ancestrais e as beberagens. Diante desse novo universo sociocultural, o trabalho dos religiosos desdobrava-se para combater os costumes e práticas construídas e vividas ao longo da história pelos povos originários da América como um todo e da Amazônia em especial. Por isso, negavam suas práticas, proibiam suas línguas e abominavam suas maneiras de ser, viver e de ver o mundo, impondo-lhes, por vezes de forma persuasiva, as regras de boas maneiras e de comportamento aos moldes da civilização européia.

É nesse contexto de combate, negação e proibição e, dada às dificuldades encontradas para converter e convencer os nativos da Amazônia, em razão, principalmente, das grandes extensões de rios e florestas, e do modo característico de viverem entre as águas e matas que os missionários da Companhia de Jesus criaram/inventaram um instrumento o Sairé - que pudesse auxiliá-los no processo de civilização dos nativos.

Esse instrumento na configuração de um semicírculo, inicialmente feito de cipó e revestido de algodão com fitas coloridas e espelhos para seduzir primeiramente as crianças indígenas, trazia no seu 
bojo a simbolização das três pessoas da Santíssima Trindade: Pai, Filho e Espírito Santo, bem como ideias, conceitos e valores da cultura ocidental.

Neste artigo, apresenta-se na primeira parte, de forma breve, o trabalho dos jesuítas no Brasil a partir da chegada da Companhia de Jesus na primeira metade do século XVI, e na sequência na Amazônia trazendose a invenção do Sairé como estratégia de convencimento, conversão e civilização dos nativos. $\mathrm{Na}$ segunda, as principais ideias apresentadas e discutidas por Norbert Elias, na sua obra O Processo Civilizador em que o trata como uma história dos costumes. É um estudo de cunho qualitativo, tendo por base a pesquisa bibliográfica e a pesquisa de campo com uso intenso de entrevistas e do registro etnográfico.

\title{
2. O TRABALHO DE CATEQUESE, INSTRUÇÃO E CIVILIZAÇÃO DOS POVOS INDÍGENAS NA AMAZÔNIA PELOS JESUÍTAS E A INVENÇÃO DO SAIRÉ
}

\author{
A parte assumida pelo elemento \\ eclesiástico, na obra da colonização, foi \\ tão extensa como salutar [...]. A \\ conquista transformou-se em missão, a \\ missão em civilização.
}

João Lúcio D'Aževedo (\{1901\}, 1999, p. 10).

Fazer uma incursão pelo projeto evangelizador e civilizatório da Companhia de Jesus permite apresentar alguns princípios que nortearam o trabalho dessa Ordem em terras brasileiras e de forma específica, no contexto da Amazônia. Com esse intuito, faz-se necessário aqui, uma breve apresentação dos métodos adotados pelos jesuítas para a conversão dos nativos ao cristianismo e aos novos valores culturais impostos em nome da fé e do império português, em especial nos aldeamentos no interior da Amazônia (DIAS, 2014).

O trabalho dos jesuítas em terras brasileiras teve início com a chegada da expedição de Tomé de Sousa (1549), primeiro governador geral do Brasil. No texto de nomeação do governador o rei de Portugal já 
deixava claro que era intenção trazer "os gentios e idólatras ao conhecimento do Nosso Senhor Jesus Cristo e de nossa fé católica para poderem salvar suas almas" (DOS SANTOS, 1992, p. 109). Embora sabedores da missão o processo de conversão desde o primeiro momento não se mostrou como uma tarefa fácil.

O padre Manuel da Nóbrega, primeiro provincial do Brasil (15531559), no Diálogo sobre a conversão do gentio, redigido em 1557, usara uma linguagem dura para demonstrar o quanto era difícil o trabalho de conversão dos indígenas, principalmente os adultos. "Por demais é trabalhar com estes; são tão bestiais, que não lhes entra no coração coisa de Deus; estão tão encarniçados em matar e comer, que nenhuma outra bemaventurança sabem desejar; pregar a estes é pregar em deserto a pedras" (DOS SANTOS, 1992, p.112). Como pode-se perceber, não só aqui, mais em todo o processo de colonização na Amazônia, vemos o fator da autoimagem do colonizador/civilizado, sobre o estabelecido/incivilizado da região.

$\mathrm{Na}$ Amazônia, as práticas religiosas adotadas pelos jesuítas, não diferente do que realizavam em outras partes do mundo, visavam fundamentalmente seduzir, convencer e converter os nativos ao cristianismo, combatendo de maneira veemente os valores culturais como a antropofagia, a poligamia, a pajelança e a nudez para torná-los não somente cristãos, mas principalmente dóceis aos diferentes serviços da Igreja e da empresa colonial portuguesa. Embora contassem com as experiências de aproximadamente um século de trabalho da Companhia no litoral brasileiro, nem sempre essa experiência era suficiente para o exercício da catequese e instrução no espaço amazônico.

Em carta de 11 de agosto de 1551, escrita em Pernambuco e envida ao padre Simão Rodrigues, em Lisboa, Nóbrega se demonstra otimista com seu trabalho" "desde que aqui estamos, [...], se fez muito fruto. Os gentios, que parecem que punham sua bem-aventurança em 
matar seus contrários, comer carne humana e ter muitas mulheres se vão muito emendando". O missionário fala da estratégia utilizada para afastar os nativos de suas práticas e costumes "e todo nosso trabalho consiste em apartá-los disso" (NÓBREGA, 2006, p. 63).

Esse otimismo inicial de Nóbrega logo dará lugar aos aborrecimentos como vimos acima quando afirma que " pregar a estes é pregar em deserto a pedras". Os aborrecimentos aparecem também nas cartas de Anchieta como se pode observar naquela escrita aos padres da Companhia em Coimbra, em março de 1555, "Estamos [...] nesta aldeia de Piratininga onde temos uma grande escola de meninos filhos de índios, já ensinados a ler e escrever, e aborrecem muito os costumes de seus pais [...]" [grifos meus]. Ter várias mulheres, comer carne humana e andar nus eram modos que aborreciam e dificultavam o trabalho dos religiosos. Através das cartas solicitavam auxilio aos superiores da Ordem e ao governo português no sentido de combater os maus costumes, como roupas para os índios cobrirem as suas vergonhas. "No dia de São Lourenço se deram algumas roupas a alguns deles, feitas de pano que o rei nos dá de esmola" (ANCHIETA, 2006, p. 128).

Nos séculos seguintes a história não fora diferente, a Companhia já fortalecida com seus aparatos teóricos e metodológicos e com a experiência adquirida, avança cada vez mais em busca de converter as almas "perdidas" nos rincões do sertão brasileiro e trazê-las ao mundo civilizado. É com essa disposição que chegam os primeiros jesuítas ao Maranhão e Grão-Pará, e começam a elaborar um ordenamento jurídico que servisse de base aos trabalhos de conversão e civilização dos nativos desta parte do Brasil, em especial nos aldeamentos.

Maia (2008), em texto intitulado REGULAMENTO DAS ALDEIAS: da Missio ideal às experiências coloniais, destaca a importância histórica das Missões ou Aldeias na experiência colonial como uma invenção dos jesuítas no Brasil. No contexto das missões documentos e 
regulamentos foram escritos com o sentido de converter, educar e civilizar os indígenas por meio de uma rotina de catequese e trabalho que visavam regular a integração e assimilação destes ao projeto colonial na Amazônia portuguesa.

Dentre os documentos destaca-se o Modo como se há de governar o gentio que há nas aldeias do Maranbão e Pará, escrito por Antônio Vieira, por volta de 1653, com o objetivo de controlar temporal e espiritualmente os nativos. No aspecto temporal o artigo 10 desse regulamento estabelecia a vigilância e cuidado com todos os índios de cada aldeia e que não saíssem fora dela, de dia, nem de noite, sem expressa licença dos padres. Isto é, os índios aldeados deveriam obedecer às ordens da Companhia tornando-se submissos aos novos modos de vida (ARENZ, 2012). Com essas medidas e mecanismos de controle as formas de imposição do padrão civilizacional ocidental cada vez mais se fortaleciam e garantiam o domínio e a expansão colonial.

É certo que mesmo com todos os recursos adotados pelos jesuítas a prática nem sempre lhe era favorável. As resistências e estratégias diante dos padrões europeus eram uma constante nos aldeamentos. $\mathrm{Na}$ missão dos Tapajós, o padre João Felipe Bettendorff relata em suas crônicas as medidas que adotara para combater as beberagens, a poligamia e o culto aos ancestrais “[...] perguntei ao alferes João Correia que cousa era esta procissão de gente, e disse-me ele que eram os índios da aldeia que iam beber e fazer suas danças que chamavam poracés no Terreiro do Diabo”. Diante desse cenário Bettendorff ordenou João Correia que avisasse aos índios que voltassem para suas casas e "quando não obedecessem ao que lhes mandava dizer, quebrasse os potes e derramasse o vinho no chão" (BETTENDORFF, 1999, p. 193). Com a mesma determinação o jesuíta fala aos índios sobre a poligamia:

Olhai os Mandamentos da Lei de Deus, todos se fundam em a razão, e quem os quiser seguir deve-se chamar homem 
racional, e pelo contrário que os não quiser seguir este se pode chamar bruto, e se deve governar com pancadas como se governam os animais irracionais. Feito este preâmbulo lhes fui propondo os Mandamentos da Lei de Deus um por um, mostrando-lhes eram mui conformes à lei da razão que Deus [...] em nossas almas. Aprovaram eles todos o que lhes praticava, e [...] perguntando se lhes se parecia bem andar com alguma mulher não sua, respondeu-me logo um que se sua mulher fizesse adultério a botaria no rio. [...] . Concordaram todos nisso $\operatorname{logo} e$ as foram entregando e pondo em um rancho grande do principal chamado de Madalena (BE'TTENDORFF, 1999, p. 194-5).

Como o discurso da Companhia era por natureza edificante, o que parece é que os índios facilmente aceitavam as ordens sem contradições, no entanto, o confronto entre as culturas era marcado pela imposição e pela resistência, e nesse jogo as estratégias utilizadas pelos missionários tinham que ser cada vez mais elaboradas no sentido de seduzir e convencer os nativos. Referindo-se aos trabalhos dos jesuítas que aportaram no Brasil em 1549, Raminelli (1996) citado por Faria (2010, p. 47), observa que Nóbrega valia-se do argumento da experiência para admitir que "a conversão pelo convencimento era inviável"; ele encontrou "na sujeição o caminho apropriado para persuadir o gentio a abraçar o cristianismo”.

Anchieta, por seu turno trabalhava com a pedagogia do exemplo, isto é, quem fizesse algo proibido pela Companhia, como "beber" e "ver festa", por exemplo, era punido publicamente e todos viam o que poderia acontecer a quem executasse a mesma coisa. Um dos exemplos era entrarem na igreja em procissão, após terem cometido algo abominável, já que era necessário um ritual de purificação para serem novamente aceitos dentro do grupo.

Apesar das imposições os jesuítas, em vários momentos, tiveram que adotar novas estratégias de conversão e se tornarem condescendentes em vários outros momentos de sua missão, devido às situações novas que se lhes impunham. Mesmo assim, no que concerne à política dos aldeamentos, o objetivo era fazer com que as proibições se efetivassem de maneira mais consistente, isto é, proibir a antropofagia, a poligamia, a 
nudez, enfim. Nóbrega já recomendava às autoridades portuguesas a existência dos aldeamentos como forma de impor temor e sujeição aos índios, dizia ele: "fazê-los viver quietos sem se mudarem para outra parte, se não for para entre cristãos, tendo terras repartidas que lhe bastem, e com estes padres da Companhia para os doutrinarem" (NÓBREGA apud FLUCK, 2013, p. 151).

Abordar o cotidiano nos aldeamentos é pensar um pouco como Michel de Certeau em $A$ invenção do cotidiano: artes de faz̧er (2012, p. 39), quando discute sobre o uso e o consumo entre colonizadores e indígenas diante da submissão e da dominação: "muitas vezes esses indígenas faziam das ações rituais, representações ou leis que lhes eram impostas outra coisa que não aquela que o conquistador julgava obter por elas". Para Certeau, os indígenas subvertiam as ordens, não as rejeitando diretamente ou modificando-as, mas pela sua maneira de usá-las para fins e em função de referências estranhas ao sistema do qual não podiam fugir. "A força de sua diferença se mantinha nos procedimentos de consumo".

Esse quadro marcado pela inversão/subversão produzido pelos considerados "mais fracos" e "sem cultura" era responsável pelo desespero dos missionários ante às atitudes dos índios frente à catequese, o que Certeau (2012) chama de "táticas", pois embora se mostrassem dispostos a tudo engolir, quando se os tinha por ganhos eis que recalcitravam, voltando ao vômito dos antigos costumes, já reclamava o padre José de Anchieta, conforme se observa em um artigo de E.V. Castro, O Mármore e a Murta: Sobre a Inconstância da Alma Selvagem (1992), o que é também reclamado por Antônio Vieira, citado no mesmo estudo.

[Os índios] recebem tudo o que lhes ensinam com grande docilidade e facilidade, sem argumentar, sem replicar, sem duvidar, sem resistir, mas são estátuas de murta que, em levantando a mão e a tesoura o jardineiro, logo perdem a nova figura, e tornam a bruteza antiga e natural, e a ser mato como dantes eram (CASTRO, 1992, p. 21). 
Nesse contexto marcado pela inconstância da alma selvagem, os jesuítas sem perderem de vista a ação evangelizadora da Companhia de Jesus e seguindo os preceitos básicos da Igreja Católica, tida nesse processo como imprescindível para resgatar o "selvagem" de sua vida desordenada e inconstante e integrá-lo à humanidade, e tendo os aldeamentos como lócus para alcançar tal objetivo em termos religiosos, sociais e culturais, inventaram o Sairé como instrumento de sedução e convencimento. Um semicírculo feito de cipó recoberto de algodão com fitas coloridas, espelhos, cruzes e toda uma simbologia acerca dessa invenção que passaria a fazer parte da dança indígena, primeiro com as crianças, como forma de dominar o nativo e trazê-lo ao mundo cristão civilizado, e depois com os adultos como mostram os primeiros registros sobre a dança que depois se transformara em festa.

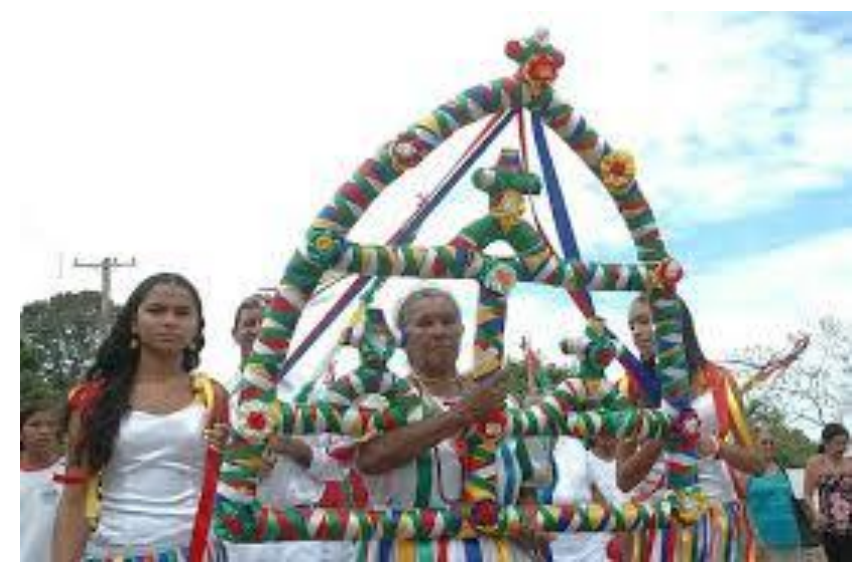

Foto 1 - Sairé criado para converter os indígenas

Fonte: Jesocarneiro.blogspot.com - 15/09/2006

O padre João Daniel, em sua obra Tesouro descoberto no máximo rio Amazonas (2004, p. 288), assim se refere ao Sairé: “Constitui o Sairé em uma boa quantidade de meninos, todos em fileiras uns atrás dos outros com as mãos nos ombros dos que lhe ficam adiante, em três, quatro ou mais fileiras [...]. O jesuíta também descreve o Sairé como uma dança em torno de um meio arco, o qual em várias travessas está enfeitado com 
algodão, flores, e outras curiosidades. Na obra Festas Amazônicas, Nogueira (2008, p. 141), afirma que "os padres jesuítas transformaram a dança da criançada indígena em instrumento de aprendizagem do catolicismo, reinventando-a com elementos da cristandade".

Em visitas pastorais à região do rio Tapajós no ano de 1762, o Bispo Dom João de São José e Queiroz, vivencia e descreve o Sairé como uma dança de acolhida acompanhada de um semicírculo ou meio arco de pau, comumente feito de cipó e recoberto de fitas coloridas:

Veio uma dança de índias às portas das casas da residência
em que estávamos, e ao seu modo dançaram muito
honestamente, tendo cinco em fileira um semicírculo ou
meio arco de pau; em que pegavam todas sustentando-o na
base que do círculo inteiro seria o diâmetro, governando uma
índia a dança, e sustentando-o com um listão preso ao
mesmo arco, alargando-o ou recolhendo quando retrocediam
ou quando ganhavam mais terreiro avançando com o dito
arco, que chamavam sayré (QUEIROZ, $\{1762\}, 1961$, p. 39 ).

Muitas são as descrições e interpretações do Sairé desde o século XVIII até os dias atuais tentando compreender o principal sentido e significado desse instrumento e da festa, na configuração sociocultural da Amazônia, a partir do processo de catequização dos povos que habitavam a planície. Nunes Pereira (1989), mostra que o uso do Sairé pelos jesuítas como estratégia de conversão e catequese dos povos indígenas da Amazônia se estendeu desde o Amapá até o Alto Rio Negro no Amazonas próximo aos limites com os domínios castelhanos. Mas é curioso observa Nogueira (2008), que o Sairé seja festejado hoje somente na Vila de Alter do Chão/PA, possivelmente no mesmo lugar onde teria iniciado.

\section{A CONQUISTA ESPIRITUAL DA AMAZÔNIA E ALGUNS CONCEITOS DE NORBERT ELIAS PARA INTERPRETAÇÃO SOCIOCULTURAL DA REGIÃO}

A conquista espiritual da Amazônia esteve diretamente ligada a um contexto do pensamento político e filosófico da Monarquia portuguesa 
dos séculos XVII e XVIII. Momento privilegiado observa Souza Júnior (2012), para se constatar a influência da filosofia jesuítica da Segunda Escolástica no pensamento político português marcado pelo movimento de Restauração do poder político de 1640, quando Portugal se liberta do domínio espanhol e retoma seu destino. Movimento que ascendeu ao trono, dom João IV, duque de Bragança.

É no contexto desse pensamento que os jesuítas chegaram ao Grão-Pará para iniciar os trabalhos de catequese junto aos nativos da região, tendo clareza de que o trabalho da Companhia de Jesus girava em torno de dois grandes polos: a política de ocupação, da Coroa portuguesa, e a ação cristianizadora dos missionários religiosos, isto é, as nações indígenas deveriam ser conquistadas para Deus e para o rei de Portugal (FRAGOSO, 1992).

É também nesse contexto de efervescência política, religiosa e de expansão territorial, que as ideias de cultura e civilização ganham força para identificar, classificar e refinar modos, costumes e comportamentos da vida humana, em especial nas cortes europeias. Norbert Elias na obra O Processo Civilizador, apresenta algumas definições do conceito de "civilização", sugerindo que esse conceito se refere a uma grande variedade de fatos: ao nível da tecnologia, ao tipo de maneiras, ao desenvolvimento dos conhecimentos científicos, às ideias religiosas e aos costumes. Afirma ainda, que pode referir-se ao tipo de habitações ou à maneira como homens e mulheres vivem juntos, à forma de punição determinada pelo sistema judiciário ou ao modo como são preparados os alimentos, entre outras (ELIAS, 2011).

Observa o autor que é sempre muito difícil sumariar em poucas palavras tudo o que se pode descrever como civilização. Mas não deixa dúvidas que o conceito expressa a consciência que o Ocidente tem de si mesmo, e mais que isso ele resume em que a sociedade ocidental dos últimos dois ou três séculos se julga superior a sociedades mais antigas ou a 
sociedades contemporâneas "mais primitivas". Com esse conceito a sociedade ocidental, na concepção de Elias, procura descrever o que lhe constitui o caráter especial e aquilo do que se orgulha: o nível de sua tecnologia, a natureza de suas maneiras, o desenvolvimento de sua cultura científica ou visão do mundo. Em que pesem essas características, faz questão de destacar que "civilização" não significa a mesma coisa para diferentes nações ocidentais, e cita exemplos do uso e sentido da palavra pela França e Inglaterra em relação à Alemanha.

Cabe aqui destacar que embora os primeiros navegantes, cronistas, religiosos e colonizadores portugueses que chegaram ao Brasil e navegaram pelo rio das Amazonas, viessem imbuídos de muitas dessas características, muitos cometeram, no mesmo processo civilizador, atrocidades em nome da civilização e de consentimento social, situação identificada por Matos (2015), como surto descivilizatório sobre os povos originários da Amazônia. A esse respeito Michel de Montaigne fez críticas ácidas à sociedade europeia, e em especial, à Igreja Católica, não somente pela forma como trataram os nativos da América "bárbaros", "selvagens", "canibais", mas por alguns comportamentos praticados na Europa.

Estimo que é mais bárbaro comer um homem vivo do que o comer depois de morto: e é pior esquartejar um homem entre suplícios e tormentos e o queimar aos poucos, ou entregá-los a cães e porcos, a pretexto de devoção e fé, como não somente o lemos mas vimos ocorrer entre vizinhos nossos e conterrâneos; e isso em verdade é bem mais grave do que assar e comer um homem previamente executado (MONTAIGNE, 1987, p. 103).

O que se depreende do processo civilizatório é a direção do autocontrole, controle das emoções e das pulsões, limiar de repugnância à violência e de vergonha desencadeado pela sociedade ocidental. Portanto, no longo curso do desenvolvimento das sociedades ocidentais o que se buscava, e ainda busca, é uma uniformidade dos comportamentos e costumes, ainda que para isso, os esforços e sacríficos estivessem para além 
das vontades individuais. Peter Burke (2008), ao debruçar-se sobre os trabalhos no campo da História Cultural, apresenta temas antes impensáveis, como a história dos costumes, e analisa trabalhos de estudiosos como Norbert Elias, por exemplo, para trazer ao debate, conceitos que serviram e servem de base para o processo civilizador. De Elias, traz os conceitos de "Fronteira da vergonha" e "Fronteira da repugnância", que segundo Burke foram gradualmente se estreitando nos séculos XVII e XVIII, excluindo da sociedade educada e/ou civilizada um número cada vez maior de formas de comportamento tidos como inadequados.

Matos (2015), apropriando-se dos principais conceitos eliasianos para produzir sua obra Ethos e Figurações na Hinterlândia Amazônica, elege alguns deles - figuração, poder, lazer, os pronomes pessoais, assim como, integração e diferenciação social -, para observar e entender o contexto sociocultural amazônico, em especial, em pequenas comunidades, bem como compreender que cada indivíduo em sua individualidade está em uma interdependência funcional com outros indivíduos. Ninguém está sozinho. Os jesuítas na tentativa de eliminarem a alma "selvagem" dos nativos, em muitos momentos tiveram que ressignificar a mensagem e negociar as relações de interdependência, permitindo o estabelecimento de um diálogo intercultural e de trocas entre culturas até mesmo por questões de sobrevivência.

$\mathrm{Na}$ compreensão de Matos (2015), o indígena não escapou ao processo civilizador ocidental. Ele absorveu e foi incrementando, à sua forma, esse modelo no contexto sociocultural de sua etnia e em suas práticas cotidianas, principalmente pelo fato de que o processo civilizatório está em curso na Amazônia. Em suas reflexões, destaca que grupos étnicos deixaram de falar sua língua original; ocorreu a informalização de seus costumes e entre outros fatos, o Pajé perdeu sua função para medicina do não índio e o seu Deus, agora é Jeová. Utilizou como referência o modo de 
vida de homens e mulheres de três comunidades amazônicas: Bicó, Cuiamucu e Canela-Fina, que dão base não apenas para extraírem e produzirem recursos para a manutenção da vida biológica, mas proporcionarem o envolvimento afetivo com o lugar de morada permitindo ampliar as figurações.

A vila de Alter do Chão, pertencente ao município de Santarém, no oeste do estado do Pará, também é um desses lugares onde a vida acontece e se realiza na relação com os rios, com a floresta, com a cidade e com as manifestações socioculturais em que os elementos simbólicos também dão sentido e significado à existência dos comunitários da vila, como, por exemplo, a festa do Sairé, que é tida como tradição do lugar, resultante do processo de evangelização e civilização dos povos Borari, e que há mais de trezentos anos faz parte dos costumes, modos e comportamentos dos descendentes desses povos originários, trazendo em sua composição elementos do cristianismo, mas também características dos nativos como o tarubá, bebida fermentada feita da mandioca, servida no Sairé.

Por fim, conclui-se que a conquista e não menos a imposição, espiritual da Amazônia esteve diretamente atrelada ao processo de conquista e ocupação do território pela coroa Portuguesa, e nesse contexto, o papel da Igreja Católica, e em especial, da Companhia de Jesus, foi primordial para dar início ao processo civilizatório, aos moldes ocidentais, junto aos indígenas da bacia amazônica. Conclui-se, ainda, que os conceitos trabalhados por Norbert Elias são fundamentais para se entender a dinâmica e a evolução desse processo na atualidade, em vários campos da ocupação humana como na agricultura, nos transportes, nos meios de comunicação, nas habitações e em comportamentos que se modificam no tempo e no espaço como resultado dos processos sociais, permitindo novas figurações e novas relações de poder. 


\section{CONSIDERAÇÕES FINAIS}

Tomando-se como base as leituras e discussões realizadas na disciplina Processo Civilizador e Práticas Socioculturais em Comunidades Amazônicas, e somadas aos conhecimentos adquiridos no decorrer do curso de mestrado sobre a missão catequética dos jesuítas na Amazônia, e o prosseguimento dessa temática no curso de doutoramento em Sociedade e Cultura na Amazônia, trazendo como tema principal a festa do Sairé na vila de Alter do Chão/PA, tornou-se mais fácil refletir sobre a formação sociocultural da região e os processos civilizatórios que desencadearam e estão presentes nessa formação.

Nessa perspectiva, espera-se que este trabalho possa contribuir para enriquecer o debate acerca do entendimento do processo civilizacional na região, compreendendo que os nativos não consumiram de forma absoluta tudo o que lhe foi imposto pelo modelo ocidental, ao contrário, reagiram, resistiram e impuseram também suas crenças e valores ressignificando práticas e comportamentos como forma não só de sobrevivência, mas de inteligência e até mesmo superioridade ao saber viver com os rios e florestas do Novo Mundo para os europeus.

\section{Referências}

ANCHIETA, José de. In: HUE, Sheila Moura. Primeiras cartas do Brasil [1551-1555]. Tradução, introdução e notas Sheila Moura Hue. Rio de Janeiro: Jorge Zahar Ed. 2006.

ARENZ, Karl Heinz. O Quotidiano nos Aldeamentos Jesuíticos na Amazônia Portuguesa (Séculos XVII e XVIII), VIII Encontro Regional de História ANPUH-PA, Belém-PA, UFPA, 2012.

Fazer sair da silva: as missões jesuiticas na Amazônia. Belém: Estudos Amazônicos, 2012. 
AZEVEDO, J. L. D. Os Jesuitas no Grão-Pará. Suas Missões e Colonização. Belém: SECULT, $\{1901\}, 1999$.

BETT'TENDORFF, João Felipe. Crônica da missão dos padres da Companhia de Jesus no estado do Maranhão. Belém: Fundação Tancredo Neves/SECULT, $\{1910\}, 1990$.

BURKE, Peter. O que é história cultural? Tradução Sérgio Góes de Paula - 2. Ed. Ver. E amp. Rio de Janeiro: Zahar, 2008.

CASTRO, Eduardo Viveiros. O mármore e a murta: sobre a inconstância da alma selvagem. Revista de antropologia, p. 21-74, 1992.

CERTEAU, Michel de. A invenção do cotidiano: artes de fazer. Trad. Ephraim Ferreira Alves. Petrópolis, RJ: Vozes, 2012.

DANIEL, João. Tesouro descoberto no Máximo Rio Amazonas. Vol. 1 e 2. Rio de Janeiro: Contraponto, 2004.

DIAS, João Aluízio Piranha. Educação colonial na Amazônia: a pedagogia dos jesuitas e a invenção do Sairé. Dissertação de Mestrado - PPGED/UEPA, Belém-PA, 2014.

DOS SANTOS, Eugenio. Índios e Missionários no Brasil Quinhentista: do confronto à cooperação. Revista da Faculdade de Letras. História, n 9, 1992, p. 107-118.

ELIAS, Norbert. O Processo Civilizador, vol. 1: uma bistória dos costumes. Tradução: Ruy Jungmann; revisão e apresentação: Renato Janine Ribeiro. $2^{\mathrm{a}}$ ed. Rio de Janeiro: Zahar, 2011.

FARIA, Marcos Roberto de. Tópicos em história da educação na América portuguesa: as representações de escola, ensino e aluno nas cartas dos primeiros jesuitas (1549-1583). Revista do Programa de Pós-graduação em Educação, Campo Grande, MS, v. 16, nº 31, p. 43-58, jan/jul. 2010.

FLUCK, Marlon Ronald. Evangelização no Brasil Colonia (Séculos XVI e XVII): Estudo comparativo de Três Modelos Missionários. Estudos Teológicos, v. 31, n. 2, p. 151-170, 2013.

FRAGOSO, Hugo. A era Missionária, In: História da Igreja na Amazônia. Petrópolis, Vozes, 1992.

MAIA, Lígio de Oliveira. Regulamento das aldeias: da Missio ideal às experiências locais. Outros Tempos, vol. 5, nº 6, Dezembro de 2008 - Dossiê Religião e Religiosidade. 
MATOS, Gláucio Campos Gomes de. Ethos e Figurações na binterlândia amazônica. Manaus, Editora Valer/Fapeam, 2015.

MONTAIGNE, Michel de. Ensaios [Dos canibais] Trad. Sérgio Milhet. $4^{\mathrm{a}}$ ed. São Paulo: Nova Cultural, 1987.

NOGUEIRA, Wilson. Festas Amarônicas: boi-bumbá, ciranda e sairé. Manaus: Editora Valer, 2008.

NÓBREGA, Manuel da. Primeiras cartas do Brasil [1551-1555]. In: HUE, Sheila Moura. Tradução, introdução e notas Sheila Moura Hue. Rio de Janeiro: Jorge Zahar Ed. 2006.

PEREIRA, Nunes. O Sabiré e o marabaixo: tradições da Amazônia. Recife: FUNDAJ, Editora Massangana, 1989.

QUEIROZ, João de São José. Visitas pastorais: memórias (1761-1762 e 1763). Rio de Janeiro: Editora Melso, 1961.

SOUZA JÚNIOR, José Alves de. Tramas do Cotidiano. Religião, politica, guerra e negócios no Grão-Pará do setecentos. Belém: ed. Ufpa, 2012. 